\title{
Suggestions on Linkage Mechanism between Medical Insurance and Hierarchical Medical System in a Southern City of Anhui Province in China: Analysis on Disease Structure of New Rural Cooperative Medical System (NCMS) Inpatients
}

Luo Meng (D1206109643@qq.com )

Anhui Medical University https://orcid.org/0000-0001-7215-3936

Ru Zhi Tang

Anhui Medical University

li Li Wang

Anhui Medical University

hua Shao Li

Anhui Medical University

Research article

Keywords: linkage mechanism, medical insurance, hierarchical medical system, disease structure, New Rural Cooperative Medical System(NCMS)

Posted Date: November 11th, 2019

DOI: https://doi.org/10.21203/rs.2.17097/v1

License: (c) (1) This work is licensed under a Creative Commons Attribution 4.0 International License. Read Full License 


\section{Abstract}

Objective: The chief aim of this paper is to explore the characteristics of medical treatment for NCMS inpatients in the central district of the southern city, and identify the main problems, so as to give some suggestions on the promotion of linkage mechanism between medical insurance and hierarchical medical system in the southern city.

Methods: Hospitalization person-times and expenses were analyzed using the medical insurance inpatients who have settled in the NCMS information management system in the central district of the sourthen city from 2013 to 2015 .

Results: Among pieces of data, there were identical 5 system diseases hospitalized both in local and nonlocal medical institutions from 2013 to 2015: respiratory system diseases, malignant neoplasms, digestive system diseases, genitourinary system diseases, and circulatory system diseases, which also ranked top 5. In the hospitalization ratio of the top 5 systemic diseases in 2015, the respiratory system accounted for the largest proportion of $95.65 \%$, and malignant neoplasms inpatients occupied the largest proportion who hospitalized in non-local medical institutions(36.27\%). The proportion of inpatients with genitourinary system diseases hospitalized in non-local medical institutions was higher(10.32\%), and the cost was lower(21.44\%), compared with that of inpatients with digestive system diseases and circulatory system diseases. We chose the 3 repesentive system diseases to analyze diseases structure: there were 4 diseases of respiratory system diseases, 7 diseases of malignant neoplasms, 3 diseases of genitourinary system diseases both hospitalized in local and non-local medical institutions.

Conclusions: All the preliminary results threw light on some defects in the process of medical treatment, which was rationality of choice and direction of diagnosis and treatment. The problem may be caused by included inpatients' incorrect medical concepts, unstandardized diagnosis and treatment behaviours, imperfect medical insurance reimbursement policy, and no adequate capacity to treat difficult and miscellaneous diseases. Under the background of deepening medical reform, the city municipal government needs to further increase the publicity of medical reform and make decisions to adapt to the changes in policy environment, for the medical insurance linkage mechanism with hierarchical medical system.

\section{Strengths And Limitations Of This Study}

- This study was based on a large number of observations, which provided sufficient statistical power to study flow direction of patients seeking medical service.

- Due to the geographical location of the study area and coverage of population, the research results have a wider influence.

- Further indepth studies should be carried out to explore individual FACTORS of medical treatment of NCMS participants, capability of precision service for the promotion of MEDICAL INSURANCE LINKAGE MECHANISM WITH HIERARCHICAL MEDICAL SYSTEM. 


\section{Background}

The goal of healthcare reform in most low-and middle-income countries is to offer universal healthcare to the public. [1] As a country with a population of around 1.4 billion, China's health reform has had an impact on global health. This is not only because China's population accounts for $20 \%$ of the world's population, but also because China's health care reform may affect other countries or regions with similar economic and social development. [2] After several decades of economic and cognitive transformation, $[3,4]$ despite impressive achievements in healthcare service delivery, the growing health needs of the population still put pressure on China's healthcare system. [5,6] Since the launch of the 2009 further healthcare reforms, China has issued a series of deepening healthcare system reform policies. [7] Local governments tailored specific measures based on local conditions within the overall policy framework. A southern city of Anhui Province, located in central China, as a relatively comprehensive area for implementing reform measures, has provided rich experiences in exploring new ways of medical reform for further reforms in other parts of China. Therefore, this study used data from this southern city to investigate the questions of interest.

To make its health system more efficient and accessible for individuals, this southern city implemented a comprehensive reform of the primary healthcare system in 2010, [8] and started a reform of county-level public hospitals in 2012. [9] In the same year, the development of the national medical insurance system was accelerated, the accessibility of insurance was stabilized, the coverage of basic medical insurance was expanded, the basic medical insurance level was continuously improved, and the medical insurance payment system was reformed. Then, in 2015, starting with the reform of urban public hospitals, the pilot medical reform was fully implemented. Different from the past, this reform focused on strengthening the system construction, giving full play to the leverage of medical insurance, building a linkage mechanism of medical insurance, and promoting the hierarchical medical system. Despite some achievements, there are still some problems that need to be solved urgently, such as insufficient coordination, fragmented systems, and irrational resource allocation. These lead to low utilization of primary health care, [10] increased medical costs, [11] and a large number of patients flowing to large hospitals in hierarchical medical systems. [12]

To solve the above problems, the Anhui provincial government required its local governments to establish various forms of medical associations, combining price, performance evaluation, and especially medical insurance, focusing on the establishment of compact medical associations and the medical community. This will gradually form a " $3+3$ " medical mechanism that performs three key tasks and improves three mechanisms, such as promoting two-way referrals and improving the health insurance payment leverage mechanism. Therefore, the linkage mechanism between medical insurance and hierarchical medical system needs further development, which is an important basis for in-depth analysis of medical procedures and disease structure. $[14,15]$ To the best of our knowledge, no study to date has been designed on how to improve the medical insurance linkage mechanism with the hierarchical medical system through the disease structure. 
We therefore selected the inpatients covered by New Rural Cooperative Medical Scheme (NCMS) in the central district of this southern city, ranked the number of inpatients treated in 2013-2015 by the location (local or non-local) of medical institutions, and analysed the structural characteristics of the diseases by taking the top ten diseases as examples.

\section{Data And Methods}

\section{Source population and Data collection}

This study was conducted within inpatients from the central district covered by NCMS. The NCMS, which is based on counties (districts), is an ongoing voluntary health insurance scheme that was established in 2003 and has continued to subsidize non-urban residents with high subsidies since then.[16] This scheme aims to reduce the risk of catastrophic health expenditures for rural residents in China. The central district is located in the southeast of Anhui Province. It is the only municipal district in transition zone between the southern city and the Yangtze River Delta from coastal to inland. From 2013 to 2015, the registered population in this central district has remained at around 860,000.

Data sources for this study comprised 65,532, 65,535 and 65,535 hospitalization records for 2013, 2014 and 2015 , covering nearly 700,000 rural residents. The main information contained in the adopted database were the general and health-related characteristics, such as ID, age, date of birth and gender; date of admission, medical institution of admission, admission departments, date of discharge, actual hospitalization days, external causes of injury or poisoning in discharge department, diagnosis information of discharge including diseases and ICD-10 coding of first diagnosis and other diagnosis, and hospitalization expenses information including fees of treatment, medicine, bed, examination, operation, laboratory, nursing, traditional Chinese medicine, and other fees.

\section{Data analysis}

Data were analysed using SPSS 16.0(IBM, USA) and EXCEL(Kingsoft, Beijing, China). First, according to ICD-10, we classified the same disease into a category called system disease. For example, the respiratory system diseases included Influenza and pneumonia, Acute upper respiratory infections, and so on. In order to investigate whether the patient's medical treatment is in line with the requirements that major diseases better be treated in the local medical structure if appropriate, we divided the hospitalization location into the local and non-local medical institutions. Second, we conducted a qualitative analysis of the number of hospitalization person-times of system diseases every year and calculated the hospitalization person-times ratio, which refers to the number of hospitalized patients with certain system diseases accounts for the total number of hospitalizations in a certain year.We have 
drawn a bar chart based on the ratio of three-year hospitalized person-times for system diseases in local and non-local medical institutions.

Then, we ranked the system diseases by the three-year hospitalized person-times ratio and listed the top ten. Third, we selected the identical five system diseases among ten listed in the last step. Based on the characteristics of the ratio of hospitalization person-times and hospitalization expenditure for each system disease, we selected three typical system diseases that performed differently (hospitalization person-times and expenditure) in local and non-local medical institutions for the further analysis of the diseases structures. Finally, we summarized the problems and possible causes of different medical treatment behaviours and put forward corresponding suggestions for the further improvement of the medical linkage mechanism.

\section{Results}

\section{The ranking of system diseases among inpatients with NCMS in the central district}

The patterns of hospitalized system diseases in the southern city were similar for each year from 2013 to 2015. For example, the proportion of malignant tumours remained at around $6 \%$. The top ten system diseases were the same, they were digestive system diseases $(\mathrm{K})$, respiratory system diseases(J), circulatory system diseases(I), genitourinary system diseases $(\mathrm{N})$, malignant neoplasms $(\mathrm{C})$, eye and appendage diseases, ear and mastoid diseases(H), injury, poisoning, and some other results of external causes(S), musculoskeletal system and ground tissue disease(M), In situ neoplasms, Benign neoplasms, Neoplasms of uncertain or unknown behaviour; Diseases of the blood and blood-forming organs and certain disorders involving the immune mechanism(D), mental and behavioural disorders(F). (Figure 1)

Note: Disease A-Z were classified according to ICD-10.

A: Certain infectious and parasitic diseases(i.e. Intestinal infectious diseases, tuberculosis);

B: Certain infectious and parasitic diseases(i.e. Viral infections, HIV diseases); C: Malignant neoplasms; D: In situ neoplasms, Benign neoplasms, Neoplasms of uncertain or unknown behaviour; Diseases of the blood and blood-forming organs and certain disorders involving the immune mechanism; E: Endocrine, nutritional and metabolic diseases; F: Mental and 
behavioural disorders; G: Nervous system diseases; H: Diseases of the ear and mastoid process; I: Circulatory system diseases; J: Respiratory system diseases; K: Digestive system diseases; L: Skin and subcutaneous diseases M: Diseases of the musculoskeletal system and connective tissue; N: Diseases of the genitourinary system; O: Pregnancy, childbirth and the puerperium; P: Certain conditions originating in the perinatal period; Q: Congenital malformations, deformations and chromosomal abnormalities; R: Symptoms, signs and abnormal clinical and laboratory findings, not elsewhere classified; S: represent S/T for Injury, poisoning and certain other consequences of external causes; U: Coding of special purpose; V: represent V/W/X/Y for external causes of morbidity and mortality; Z: Factors influencing health status and contact with health services

*The ratio of the system disease $\alpha$ hospitalized in the local medical institutions $=$ the number of local inpatients with the system disease $\alpha$ / the total number of local inpatients The total number of local inpatients $=\sum$ the number of local inpatients with disease $\beta$ ( $\beta$ represents disease $\mathrm{A}$ to $\mathrm{Z}$ )

As shown in Figure 2, the ratios of system diseases were similar for each year from 2013 to 2015, such as endocrine, nutritional and metabolic diseases, which accounts for about 3\%. Over the past three years, the top ten system diseases hospitalized in the non-local medical institutions had the same ranking as those hospitalized in the local medical institutions. The following identical eight system diseases ranked in the top ten during 2013-2015. They were malignant neoplasms(C), circulatory system diseases(I), digestive system diseases(K), Musculoskeletal system and ground tissue disease(M), genitourinary system diseases(N), In situ neoplasms, Benign neoplasms, Neoplasms of uncertain or unknown behaviour; Diseases of the blood and blood-forming organs and certain disorders involving the immune mechanism(D), respiratory system diseases(J), Endocrine, nutritional and metabolic diseases(E), Factors affecting health status and access to health services(Z), Symptoms, signs and abnormal clinical and laboratory findings, not elsewhere classified(R). However, there was a slight difference in the ranking list from 2013 to 2015. Nervous system diseases $(G)$ and symptoms, signs and abnormal clinical and laboratory findings, not 
elsewhere classified(R) were in top10 in 2013』while diseases of the ear and mastoid process $(\mathrm{H})$ and factors influencing health status and contact with health services $(\mathrm{Z})$ were in top 10 both in 2014 and 2015 list.

Note:A-Z were explained above; the formula of ratio is the same as above

Figure 1 and 2 showed that from 2013 to 2015, the ratios of hospitalizations for each system disease were similar. In 2015, the top five system diseases hospitalized both in the local and non-local medical institutions were respiratory system diseases, digestive system diseases, circulatory system diseases, genitourinary system diseases and malignant tumours. Regardless of the disease's hospitalized location, the total ratio of the top five system diseases was about $70 \%$.

Table 1. The hospitalization person-times and expenses of the top 5 system diseases hospitalized in in-city and out-of-city medical institutions in 2015

\begin{tabular}{ccccc}
\hline Diseases & \multicolumn{2}{c}{ hospitalization person-times } & \multicolumn{2}{c}{ hospitalization expenses(1m $¥)$} \\
\cline { 2 - 5 } & $\begin{array}{c}\text { Local medical } \\
\text { institutions }\end{array}$ & $\begin{array}{c}\text { Non-local } \\
\text { medical } \\
\text { institutions }\end{array}$ & $\begin{array}{c}\text { Local medical } \\
\text { institutions }\end{array}$ & $\begin{array}{c}\text { Non-local } \\
\text { medical } \\
\text { institutions }\end{array}$ \\
\hline Respiratory & 9304 & 423 & 28.42 & 4.25 \\
system diseases & $(95.65 \%)$ & $(4.35 \%)$ & $(87.00 \%)$ & $(13.00 \%)$ \\
Malignant & 3633 & 2068 & 29.28 & 3.89 \\
neoplasms & $(63.73 \%)$ & $(36.27 \%)$ & $(42.96 \%)$ & $(57.04 \%)$ \\
Digestive system & 9577 & 988 & 44.32 & 14.43 \\
diseases & $(90.65 \%)$ & $(9.35 \%)$ & $(75.44 \%)$ & $(24.56 \%)$ \\
Genitourinary & 6057 & 697 & 26.16 & 7.14 \\
system diseases & $(89.68 \%)$ & $(10.32 \%)$ & $(78.56 \%)$ & $(21.44 \%)$ \\
Circulatory & 8081 & 819 & 47.24 & 21.28 \\
system diseases & $(90.80 \%)$ & $(9.20 \%)$ & $(68.94 \%)$ & $(31.06 \%)$ \\
\hline
\end{tabular}

* The proportion of disease $\alpha=$ the hospitalized person-times (hospitalization expenses) of disease $\alpha$ in the local (non-local) medical institutions / the total hospitalized person-times (hospitalization expenses) of disease $\alpha$ 
Total number of inpatients (hospitalization expenses) with disease $\alpha=$ the hospitalized person-times (hospitalization expenses) of disease $\alpha$ in the local medical institutions + the hospitalized person-times (hospitalization expenses) of disease $\alpha$ in the non-local medical institutions

Table 1 shows that compared with 95.65\% of inpatients with respiratory diseases treated in the local medical institutions, only $4.35 \%$ were treated in non-local medical institutions. Its hospitalization expenses had the same trend. Compared with $87 \%$ of the hospitalization expenses incurred in local medical institutions, only 13\% of the expenses incurred in nonlocal medical institutions. It is worth noting that compared with the other four diseases, Malignant neoplasms inpatients accounted for the largest proportion (36.27\%) of the inpatients who chose non-local medical institutions, while its hospitalization expenses accounted for $57.04 \%$ of the total medical expenses of non-local medical institutions. Compared with digestive system diseases or circulatory system diseases, another interesting result was that the proportion of inpatients with genitourinary system diseases who went to non-local medical institutions was higher than those hospitalized in local medical institutions, but its expense incurred in non-local medical institutions was lower than that incurred in local medical institutions. Therefore, in order to better understand the above results, we further analysed the disease structures of respiratory diseases, malignant neoplasms, and genitourinary diseases.

Analysis of disease structure of respiratory diseases, malignant tumors and genitourinary diseases hospitalized in local and non-local medical institutions

Disease structure of respiratory diseases hospitalized in local and non-local medical institutions

Table 2 shows that among the top ten diseases of the respiratory system, regardless of the patients hospitalized in local or non-local medical institutions, there were four of the same 
diseases: pulmonary atypical hyperplasia, atypical pneumonia, chronic obstructive pulmonary disease and acute exacerbation of chronic obstructive emphysema bronchitis. Chronic obstructive pulmonary disease is ranked second among the diseases hospitalized in local medical institutions and forth in non-local medical institutions. Diseases such as pulmonary atypical hyperplasia, atypical pneumonia and chronic obstructive pulmonary disease were all ranked in the top four, regardless of whether the patients with these diseases hospitalized in local or non-local medical institutions. Comparing the 'local' list of the top ten diseases with the 'non-local' list, we found that six diseases were different, especially vocal cord polyp. The ranked proportion of its non-local hospitalization was the third (6.6\%).

Table 2. Structure of respiratory diseases hospitalized in local and non-local medical institutions 


\begin{tabular}{|c|c|c|c|c|c|}
\hline Rank & Diseases & $\begin{array}{l}\text { The ratio of } \\
\text { hospitalization } \\
\text { person-times in } \\
\text { local medical } \\
\text { institutions } \\
(\%)\end{array}$ & Rank & Diseases & $\begin{array}{c}\text { The ratio of } \\
\text { hospitalization } \\
\text { person-times } \\
\text { in non-local } \\
\text { medical } \\
\text { institutions } \\
\text { (\%) }\end{array}$ \\
\hline 1 & Bronchitis & 14.7 & 1 & $\begin{array}{l}\text { Lung atypical } \\
\text { hyperplasia }\end{array}$ & 13.7 \\
\hline 2 & $\begin{array}{l}\text { Chronic obstructive } \\
\text { pulmonary disease }\end{array}$ & 11.5 & 2 & $\begin{array}{l}\text { Atypical } \\
\text { pneumonia }\end{array}$ & 7.6 \\
\hline 3 & $\begin{array}{l}\text { Lung atypical } \\
\text { hyperplasia }\end{array}$ & 10.7 & 3 & $\begin{array}{l}\text { Vocal cord } \\
\text { polyp }\end{array}$ & 6.6 \\
\hline 4 & $\begin{array}{l}\text { Atypical } \\
\text { pneumonia }\end{array}$ & 10.5 & 4 & $\begin{array}{l}\text { Chronic } \\
\text { obstructive } \\
\text { pulmonary } \\
\text { disease }\end{array}$ & 5.2 \\
\hline 5 & Acute bronchitis & 9.6 & 5 & Pleural effusion & 3.8 \\
\hline 6 & Chronic bronchitis & 9.4 & 6 & Lung injury & 3.8 \\
\hline 7 & Bronchopneumonia & 4.2 & 7 & $\begin{array}{l}\text { Chronic } \\
\text { odontogenic } \\
\text { sinusitis }\end{array}$ & 2.6 \\
\hline 8 & $\begin{array}{l}\text { Chronic obstructive } \\
\text { emphysema } \\
\text { bronchitis with } \\
\text { acute exacerbation }\end{array}$ & 3.5 & 8 & $\begin{array}{l}\text { Chronic } \\
\text { obstructive } \\
\text { emphysema } \\
\text { bronchitis with } \\
\text { acute } \\
\text { exacerbation }\end{array}$ & 2.6 \\
\hline 9 & $\begin{array}{l}\text { Upper respiratory } \\
\text { tract infection }\end{array}$ & 3.4 & 9 & $\begin{array}{l}\text { Respiratory } \\
\text { failure }\end{array}$ & 2.6 \\
\hline 10 & $\begin{array}{l}\text { Acute upper } \\
\text { respiratory tract } \\
\text { infection }\end{array}$ & 2.3 & 10 & $\begin{array}{l}\text { Spontaneous } \\
\text { pneumothorax }\end{array}$ & 2.4 \\
\hline
\end{tabular}


Table 3 shown that the malignant neoplasms treated in medical institutions were: bronchial malignancy, gastric ulcer cancer, premalignant breast tumour, rectal malignancy, hepatic malignancy, bronchial and pulmonary malignancies. And, notably, gastric ulcer cancer, premalignant breast tumour and bronchial malignancy were the top three diseases in the 'local' and 'non-local' lists. In the meanwhile, the other three diseases out of top ten with the non-local hospitalization were nasopharyngeal malignant tumour, breast malignancy, malignant tumour. They were differed from the diseases hospitalized in the local medical institutions and ranked 6th (3.4\%), 8th (2.9\%), 9th (2.9\%), respectively.

Table3.Diseases' structure of malignant neoplasms in in-city and out-of-city medical institutions 


\begin{tabular}{|c|c|c|c|c|c|}
\hline Rank & $\begin{array}{l}\text { Diseases } \\
\text { structure }\end{array}$ & $\begin{array}{c}\text { The ratio of } \\
\text { hospitalization } \\
\text { person-times in local } \\
\text { medical institutions } \\
\text { (\%) }\end{array}$ & Rank & $\begin{array}{l}\text { Diseases } \\
\text { structure }\end{array}$ & $\begin{array}{c}\text { The ratio of } \\
\text { hospitalization } \\
\text { person-times } \\
\text { in non-local } \\
\text { medical } \\
\text { institutions }\end{array}$ \\
\hline 1 & $\begin{array}{l}\text { Bronchial } \\
\text { malignancy }\end{array}$ & 19.9 & 1 & $\begin{array}{l}\text { Gastric ulcer } \\
\text { cancer }\end{array}$ & $\frac{(\%)}{9.6}$ \\
\hline 2 & $\begin{array}{l}\text { Gastric ulcer } \\
\text { cancer }\end{array}$ & 13.5 & 2 & $\begin{array}{l}\text { Paramalignant } \\
\text { breast tumor }\end{array}$ & 8.1 \\
\hline 3 & $\begin{array}{l}\text { Paramalignant } \\
\text { breast tumor }\end{array}$ & 11.3 & 3 & $\begin{array}{l}\text { Bronchial } \\
\text { malignancy }\end{array}$ & 7.8 \\
\hline 4 & $\begin{array}{l}\text { Colonic } \\
\text { malignancy }\end{array}$ & 5.7 & 4 & $\begin{array}{l}\text { Bronchial and } \\
\text { pulmonary } \\
\text { malignancies }\end{array}$ & 5.2 \\
\hline 5 & $\begin{array}{l}\text { Rectal } \\
\text { malignancy }\end{array}$ & 5.5 & 5 & $\begin{array}{l}\text { Rectal } \\
\text { malignancy }\end{array}$ & 4.9 \\
\hline 6 & $\begin{array}{l}\text { Hepatic } \\
\text { malignancy }\end{array}$ & 4.0 & 6 & $\begin{array}{l}\text { Nasopharyngeal } \\
\text { malignant } \\
\text { tumor }\end{array}$ & 3.4 \\
\hline 7 & $\begin{array}{l}\text { Ovarian } \\
\text { malignancy }\end{array}$ & 3.9 & 7 & $\begin{array}{l}\text { Hepatic } \\
\text { malignancy }\end{array}$ & 3.2 \\
\hline 8 & $\begin{array}{l}\text { Bronchial and } \\
\text { pulmonary } \\
\text { malignancies }\end{array}$ & 3.3 & 8 & $\begin{array}{l}\text { Breast } \\
\text { malignancy }\end{array}$ & 2.9 \\
\hline 9 & $\begin{array}{l}\text { Esophageal } \\
\text { malignancy }\end{array}$ & 3.2 & 9 & $\begin{array}{l}\text { Malignant } \\
\text { tumor }\end{array}$ & 2.9 \\
\hline 10 & Leukemia & 2.1 & 10 & $\begin{array}{l}\text { Colonic } \\
\text { malignancy }\end{array}$ & 2.6 \\
\hline
\end{tabular}

Disease structure of genitourinary system diseases hospitalized in local and non-local medical institutions

As shown in Table 4, the disease structure of urogenital diseases hospitalized in local and non-local medical institutions was different, including only three identical diseases: ureteral calculi, chronic renal failure and endometrial polyps. For example, ureteral calculi ranked 
$2^{\text {nd }}$ in local medical institutions while ranked $1^{\text {st }}$ in non-local medical institutions. Women are the main inpatients for urogenital diseases, including pelvic cyst, endometrial polyps, dysfunctional uterine bleeding, cervicitis, endometritis and adenomyoma. Among the top ten diseases hospitalized in medical institutions, there were seven genitourinary system diseases. For example, the ratio of hospitalization person-times of kidney stones which hospitalized in non-local medical institutions was $5.9 \%$ and ranked $2^{\text {nd }}$.

Table 4. Structure of genitourinary system diseases visited in the city and out-of city medical institutions. 


\begin{tabular}{|c|c|c|c|c|c|}
\hline Rank & Diseases & $\begin{array}{l}\text { The ratio of } \\
\text { hospitalization } \\
\text { person-times in } \\
\text { local medical } \\
\text { institutions } \\
\text { (\%) }\end{array}$ & Rank & Diseases & $\begin{array}{c}\text { The ratio of } \\
\text { hospitalization } \\
\text { person-times } \\
\text { in non-local } \\
\text { medical } \\
\text { institutions }\end{array}$ \\
\hline 1 & Pelvic cyst & 6.1 & 1 & Ureteral calculi & $\frac{(\%)}{10.0}$ \\
\hline 2 & $\begin{array}{l}\text { Ureteral } \\
\text { calculi }\end{array}$ & 6.0 & 2 & Kidney stones & 5.9 \\
\hline 3 & $\begin{array}{l}\text { Endometrial } \\
\text { polyps }\end{array}$ & 5.2 & 3 & $\begin{array}{l}\text { Chronic renal } \\
\text { failure }\end{array}$ & 3.7 \\
\hline 4 & $\begin{array}{l}\text { Chronic renal } \\
\text { failure }\end{array}$ & 5.1 & 4 & $\begin{array}{l}\text { Grade I cervical } \\
\text { intraepithelial } \\
\text { neoplasm }\end{array}$ & 3.4 \\
\hline 5 & $\begin{array}{l}\text { Calculous } \\
\text { pyelonephritis }\end{array}$ & 5.0 & 5 & Nephritic nephritis & 3.2 \\
\hline 6 & $\begin{array}{l}\text { Dysfunctional } \\
\text { uterine } \\
\text { bleeding }\end{array}$ & 3.9 & 6 & $\begin{array}{l}\text { Chronic renal } \\
\text { insufficiency }\end{array}$ & 2.9 \\
\hline 7 & Cervicitis & 3.6 & 7 & Ovarian cyst & 2.9 \\
\hline 8 & Endometritis & 3.5 & 8 & $\begin{array}{l}\text { Endometrial } \\
\text { polyps }\end{array}$ & 2.9 \\
\hline 9 & $\begin{array}{l}\text { Asymptomatic } \\
\text { bacteriuria }\end{array}$ & 3.3 & 9 & $\begin{array}{l}\text { Chronic } \\
\text { glomerulonephritis }\end{array}$ & 1.9 \\
\hline 10 & $\begin{array}{l}\text { Uterine } \\
\text { adenomyoma }\end{array}$ & 2.9 & 10 & $\begin{array}{l}\text { Ureteral } \\
\text { obstruction }\end{array}$ & 1.9 \\
\hline
\end{tabular}

\section{Discussion}

This study described the distribution and composition of system diseases hospitalized with local and non-local medical institutions of a southern city of Anhui province in China. The data in this study was extracted from a regular database that included a total of 196,602 records of NCMS inpatients in the central district of the southern city of interest during 2013-2015. This analysis suggested that the proportion of hospitalization for each system disease was relatively stable from 2013 to 2015 . No matter whether the patients in this southern city were hospitalized in local or non-local medical institutions, the top five causes (system diseases) are the same and the total proportion of these five causes is about 
$70 \%$, while the system diseases structures are different. The listed three typical system diseases perform differently in hospitalization person-times and expenditure. For example, atypical pulmonary hyperplasia accounted for a high proportion of hospitalizations in both locations. The kidney stone was in the top ten disease list of reasons for hospitalization in non-local medical institutions, but not in the list of reasons for hospitalization in local medical institutions. According to the overall policy framework of Chinese healthcare reform, the local inpatients need to be guided to choose local medical institutions for hospitalization and refer to non-local medical institutions if necessary. Therefore, it is necessary to further analyse the reasons that local inpatients choose non-local medical institutions.

There are several explanations that may explain this. The family member of the local family works and lives in another city. Once their family members get sick, they normally go to the medical institutions where they work and live in because of convenience. [17] If the local medical technology level does not meet the needs of the local patients, such as outdated equipment and inexperienced doctors, $[18,19]$ it is easy to understand that their non-local hospitalized behaviours. Sometimes, the patients went to the local medical institutions initially, but were told by the doctors to refer to other non-local medical institutions with a better medical environment than theirs. [20] The benefits drove some doctors in the non-local medical institutions to mislead patients to choose unnecessary hospitalization because patients are more likely to rely on the medical institutions with high medical technology and advanced facilities and lack relevant professional medical knowledge. [21] Therefore, it is necessary to adjust the patient's medical behaviour cognition. [22] Since the medical insurance system has bridged hospitals and patients [23] it is of vital importance to use the medical insurance system rationally to solve the problems of the flow direction of inpatients. This study also showed that the leverage of medical insurance needs to be strengthened in the medical system of this southern city to guide the reasonable flow of inpatients in the hierarchical medical system.

On the basis of summarizing the healthcare-seeking behaviour of inpatients, here are some suggestions on how to further improve the medical insurance linkage mechanism with the hierarchical medical system.

\section{Make action plans for key clinical disciplines to improve the ability of local medical institutions}

First, according to the number of patients in the local medical institutions, the development of the medical service system, hospitalization expenses and their proportion in system diseases, the local policymakers should determine the dominant disciplines, key disciplines and weak disciplines for the local medical institutions. Then, they could focus on dominant disciplines, establish key disciplines, and vigorously strengthen the construction of weak disciplines. The cost of cancer in China has exploded in the past few decades, [24,25] and this rapid growth trend is likely to continue. [26] As the shown result of this study, oncology, especially malignant tumours in organs such as digestive system, breast and 
respiratory tract, as a weak discipline, can be strengthened by establishing medical associations and medical service communities.

When the local medical institutions have excellent medical standards, it will enhance the local people's trust, then they are more willing to go to the local medical institutions. [27] Therefore, to improve the professional medical skills of inexperienced local doctors, the local government needs to make policies to attract more non-local but experienced doctors to local medical institutions by establishing medical associations. [28] The local medical institutions can develop special aspects that could attract certain patients to visit. Some local medical institutions are the major teaching institutions, so developing the disciplines in education may also benefit. For example, developing the discipline of the integrated Chinese and Western medicine is helpful to connect these two medical systems which have been developed separately in history. [29]

The local government has the responsibility to supervise and promote the development of local medical technology. [30] Through improving the local medical level of common diseases, frequently occurring diseases, major diseases and acute and critical diseases, patients can be attracted and retained by appropriate medical technologies. In addition, the village and township hospitals could attract more inpatients by low-priced but qualified service. [31]

\section{Improve the reimbursement policy for differential medical insurance and establish a dynamic adjustment mechanism for medical insurance}

Medical insurance compensation policy is one of the main means to guide the healthcare-seeking behaviour of inpatients. Therefore, the local government should pay more attention to improving the insurance compensation policy, further improve the medical reimbursement ratio at different levels and different regions, [32,33,34] and implement a full prepayment system for medical communities. [35] Further effort is needed to improve the comprehensive NCMS benefit package by expanding the drug list and reimbursement scope, increasing reimbursement rates and changing the behaviour of health care providers through payment reform. [36,37,38] Meanwhile, for making a better leverage role of medical insurance, the local government ought to establish a dynamic change mechanism of medical insurance.

\section{Standardize referral process and strengthen health policy propaganda}

Taking the city as a unit, we suggest establishing a referral management system for basic medical insurance, strictly regulate the referral conditions and procedures [39] correctly guide inpatients and avoid unnecessary referrals. In this process, the medical insurance fund management organization plays an important role. To strengthen the management of referral, it is necessary to strictly review the nature of the medical institutions selected by the patients during the referral, and to implement a two-way referral continuous calculation deduction system between medical institutions, so as to guide inpatients to 
choose primary medical institutions for initial diagnosis, which further promotes the perfection of the two-way referral system. [40] Supervision and inspection of the operation of the referral system in local hospitals should be strengthened, and the doctors' referral notification should be reviewed strictly and regularly. [41]

Some patients too depend on large medical institutions to face up to their own needs and make rational judgments, [42] resulting in the coexistence of waste and scarcity of medical resources. Education and publicity have been proven to be useful and effective in strengthening the knowledge of health policy and hierarchical medical system, but in fact, they have not been fully utilized. [43] Therefore, how to make the ways of education and publicity, such as brochures, networks, news media and publicity boards, [43] really work is challenging. This challenge is not only for patients but also for health workers, especially the primary health workers. [44] The government should establish designated medical institutions and medical insurance reimbursement policies to guide correct two-way medical-seeking behaviours. $[45,46]$

\section{Conclusions}

This study found that a large proportion of inpatients in this southern city chose non-local medical institutions for medical care, posing challenges for local government and local medical institutions. The medical choices and directions of local inpatients still need further adjustment, and the linkage mechanism between medical insurance and hierarchical medical system may be an effective means. As the first study to explore how to improve the linkage mechanism of medical insurance based on the hierarchical medical system of disease structure through a large database, this study provides a medical reform idea for cities or regions with similar economic and social development in China to establish a tailored linkage mechanism between medical insurance and hierarchical medical system.

\section{References}

1.Lagomarsino, G., Garabrant, A., Adyas, A., Muga, R., Otoo, N., 2012. Moving towards universal health coverage: health insurance reforms in nine developing countries in Africa and Asia. Lancet 380, 933-943.

2.Miao Y,Gu J,Zhang L,He R,Sandeep S,Wu J. Improving the performance of social health insurance system through increasing outpatient expenditure reimbursement ratio: a quasi-experimental evaluation study from rural China.Int J Equity Health.2018; 17(1):89.

3.Yang G, Kong L, Zhao W, Wan X, Zhai Y, et al. 2008. Emergence of chronic non-communicable diseases in China. Lancet 372:1697-705.

4.Yang GH, Wang Y, Zeng YX, Gao GF, Liang XF, et al. 2013. Rapid health transition in China, 1990-2010: findings from the Global Burden of Disease Study 2010. Lancet 381:1987-2015.

5.Liu Gordon G, Vortherms, Samantha A, Hong Xuezhi. China's Health Reform Update. Annual Review of Public Health 2019:I2378. 
6.Burns R, Liu GG. 2016. China's Healthcare System and Reform. Cambridge, UK: Cambridge Univ. Press.

7.Meng Q,Mills A,Wang L,Han Q. What can we learn from China's health system reform? BMJ.2019 365():12349.

8.Anhui Provincial People's Government. Implementation Opinions of the People's Government of Anhui Province on the Comprehensive Reform of Grassroots Medical and Health Systems [Z].2009.

9.Gao Kaiyan. Report on the progress of the pilot comprehensive reform of the basic medical and health system in Anhui Province [J]. China rural health administration, 2010,30 (07): 515-517.

10.Ma X, Wang H, Yang L, Shi L, Liu X. Incentivising China's primary health care providers.BMJ 2019;365:I2406. doi:10.1136/bmj.I2406.

11.Xu J, Jian W, Zhu K, Kwon S, Fang H. Reforming public hospital financing in China: progress and challenges.BMJ 2019;365:I4015. doi:10.1136/bmj.I4015.

12.Fang $\mathrm{H}$, Eggleston $\mathrm{K}$, Hanson $\mathrm{K}$, Wu M.Enhancing financial protection under China's social health insurance to achieve universal health coverage. BMJ 2019;365: I2378. doi:10.1136/bmj.I2378.

13.City Government (Office). Urban Health Service System Planning (2016-2020). http://www.xuancheng.gov.cn/openness/detail/content/5915102f20f7feca24cc4a73.html.

14.. Hindhede AL, Bonde A, Schipperijn J, et al. How do socio-economic factors and distance predict access to prevention and rehabilitation services in a Danish municipality? Prim Health Care Res Dev. 2016;17:578-85.

15.Schlichthorst M, Sanci LA, Pirkis J, et al. Why do men go to the doctor? Socio-demographic and lifestyle factors associated with healthcare utilization among a cohort of Australian men. BMC Public Health. 2016;16:81-90.

16.You, X., \& Kobayashi, Y. (2009). The new cooperative medical scheme in China. Health policy, 91(1), 19.

17.J. Mou, J. Cheng, D. Zhang, H. Jiang, L. Lin, and S. M. Grifths,“Health care utilisation amongst Shenzhen migrant workers: Does being insured make a diference?"BMC Health Services Research, vol. 9, 2009.

18.Barbara S, Shi L, James M. Contribution of primary care to health systems and health. The Milbank Quarterly. 2005;83:457-502.

19.Natale-Pereira A, Enard KR, Nevarez L, et al. The role of patient navigators in eliminating health disparities. Cancer. 2011;117:3543-52. 
20.Atkinson S, Ngwengwe A, etl. The referral process and in-city health care in sub-Saharan Africa: the case of Lusaka, Zambia.Soc Sci Med. 1999;49(1):27-38.

21.Miguel, E.; Kremer, M. Worms: Identifying Impacts on Education and Health in the Presence of Treatment Externalities. Econometrica 2004, 72, 159-217.

22.Brown P.H., Theoharides C. Health-seeking behavior and hospital choice in China's New Cooperative Medical System. Health Econ. 2009, 18, S47-S64.

23.Xiong Xiaolei, Zhang Zhiguo, Ren Jing. Impact of universal medical insurance system on the accessibility of medical service supply and affordability of patients in China. PLOS ONE 2018, 13:3. DOI: 10.1371/journal.pone.0193273.

24.Lee KS, Chang HS, Lee SM, Park EC. Economic Burden of Cancer in Korea during 2000-2010. Cancer Res Treat. 2015;47(3):387-98.

25.Trogdon JG, Tangka FK, Ekwueme DU, Guy Jr GP, Nwaise I, Orenstein D. State-level projections of cancer-related medical care costs: 2010 to 2020. Am J Manag Care. 2012;18(9):525-32.

26.Zhao T, Cheng J, Chai J, etl.Inpatient care burden due to cancers in Anhui, China: a cross-sectional household survey.BMC Public Health. 2016 Apr 11;16:308.

27.Tuan T, Dung VTM, Neu I, Dibley MJ: Comparative quality of private and public health services in rural Vietnam. Health Policy Plan 2005, 20:319-27.

28.Chinese Ministry of Health Centre for Health Statistical Information: Abstract of the report on the 3rd National Health Service investigation and analysis. Chin Hosp. 2005, 9: 7-15.

29.Miao Hua, Jingyi Fan, Hongmei Dong, and Renslow Sherer .Integrating traditional Chinese medicine into Chinese medical education reform: issues and challenges.Int J Med Educ. 2017; 8: 126-127.

30.The Central People's Government of the People's Republic of China: The central finance funding 10.4 billion Yuan for basic public health services. 2009, Government of the People's Republic of China website. Available: http://www.gov.cn/gzdt/2009-07/06/content_1358394.htm. In Chinese. Accessed 2009 Jul 15.

31.Wang X, He X, Zheng A, Ji X. The effects of China's new cooperative medical scheme on accessibility and affordability of healthcare services: An empirical research in Liaoning Province. BMC Health Serv Res 2014;14:388.

32.Xiang L, Pan Y, Hou S, Zhang H, Sato KD, Li Q, et al. The impact of the new cooperative medical scheme on financial burden of tuberculosis patients: Evidence from six counties in China. Infect Dis Poverty 2016;5:8. doi: 10.1186/s40249-015-0094-5. 
33.Wang J, Chen L, Ye T, Zhang Z, Ma J. Financial protection effects of modification of China's new cooperative medical scheme on rural households with chronic diseases. BMC Health Serv Res 2014;14:305. doi: 10.1186/1472-6963-14-305.

34.Jing S, Yin A, Shi L, Liu J. Whether new cooperative medical schemes reduce the economic burden of chronic disease in rural China. PLoS One 2013;8:e53062. doi: 10.1371/journal.pone.0053062.

35.Yang X, Gao J, Zhou Z, et al. Assessing the Effects of the New Cooperative Medical Scheme on Alleviating the Health Payment-Induced Poverty in Shaanxi Province, China. PLOS ONE, 2016; 11(7).https://doi.org/10.1371/journal.pone.0157918 PMID: 27380417.

36.Yang L, Liu L, Yang L, Zhao G, Cao D. Medical education Reform of China in the Global Context. Chinese Journal of Medical Education Research. 2012; 11(5): 457-459.

37.Gao T, Shiwaku K, Fukushima T, Isobe A, Yamane Y. Medical education in China for the 21st century. Med Educ. 1999;33:768-773.

38.Jiang Xiangli. National Health and Wellness Conference: Blowing the Horn of the Construction of Healthy China[J]. China Science and Technology Industry, 2016(9).

39.Jones CA, Mawani S, King KM, Allu SO, Smith M, Mohan S, et al. Tackling health literacy : adaptation of public hypertension educational materials for an indo-Asian population in Canada. BMC Public Health. 2011;11:24. https://doi.org/10.1186/1471-2458-11-24 PMID: 21223580.

40.Barber SL, Yao L. Health insurance systems in China: A briefing note. World Health Report (2010).Background Paper 37. Geneva, Switzerland: World Health Organization;http://www.who.int/healthsystems/topics/financing/healthreport/37ChinaB_YFINAL.pdf. Accessed 10-8.

41.Brown S, Castelli M, Hunter DJ, et al. How might healthcare systems influence speed of cancer diagnosis: a narrative review. Soc Sci Med. 2014;116:56-63.

42.Singh S. Self-referral to accident and emergency department: patients' perceptions. BMJ. 1988;297:1179-80.

43.Friedberg MW, Hussey PS, Schneider EC. Primary care: a critical review of the evidence on quality and costs of health care. Health Aff (Millwood). 2010;29:766-70.

44.Tang SF, Ji L, Hu T, et al. Determinants of public malaria awareness during the national malaria elimination programme: a cross- sectional study in rural China. Malar J. 2016;15(1):372.

45.Tang SF, Dong D, Ji L, et al. What contributes to the activeness of ethnic minority patients with chronic illnesses seeking allied health services? A cross-sectional study in rural western China. Int J Environ Res Public Health. 2015;12(9):11579-93. 
46.Sun $X$, Chen $Y$, Tong $X$, et al. The use of annual physical examinations among the elderly in rural China: a cross-sectional study. BMC Health Serv Res. 2014;14(1):1-8.

\section{Declarations}

\section{Ethics approval and consent to participate}

Not applicable.

\section{Patient and Public Involvement statement}

Patients or the public were not involved in the design, or conduct, or reporting, or dissemination plans of our research.

\section{Consent for publication}

All authors agree to publish.

\section{Consent for publication}

All authors have approved the final manuscript and consented for the publication.

\section{Availability of data and material}

The data that support the findings of this study are available from basic medical insurance information management system in the central district of the southern city, but restrictions apply to the availability of these data, which were used under license for the current study, and so are not publicly available. Data are available from the authors upon reasonable request and with permission of basic medical insurance information management system in the central district.

\section{Competing interests}

We have read and understood BMJ policy on declaration of interests and declare that we have no competing interests. 


\section{Funding}

This project was commissioned by the Southern City Health and Family Planning Commission.

\section{Authors' contributions}

All authors participated in the study conception and design. Associate professor ZT and ML are co-first authors of the article. Associate professor ZT provided data, interpretation of results and policy recommendations. ML performed the statistical analysis and drafted the paper. Dr LW and ML revised the paper, and professor SL proposed constructive amendments to the draft. All authors read and approved the final manuscript.

\section{Acknowledgement}

Thanks for the support of the relevant staff.

\section{Authors' information}

${ }^{1}$ School of Health Management, Anhui Medical University, Hefei 230032, China. ${ }^{1}$ School of Health Management, Anhui Medical University, Hefei 230032, China.

${ }^{2}$ School of Health Management, Anhui Medical University, Hefei 230032, China. ${ }^{3}$ School of Health Management, Anhui Medical University, Hefei 230032, China.

Correspondence to

Professor Shaohua Li; 1425051920@qq.com

\section{Figures}




\section{8}

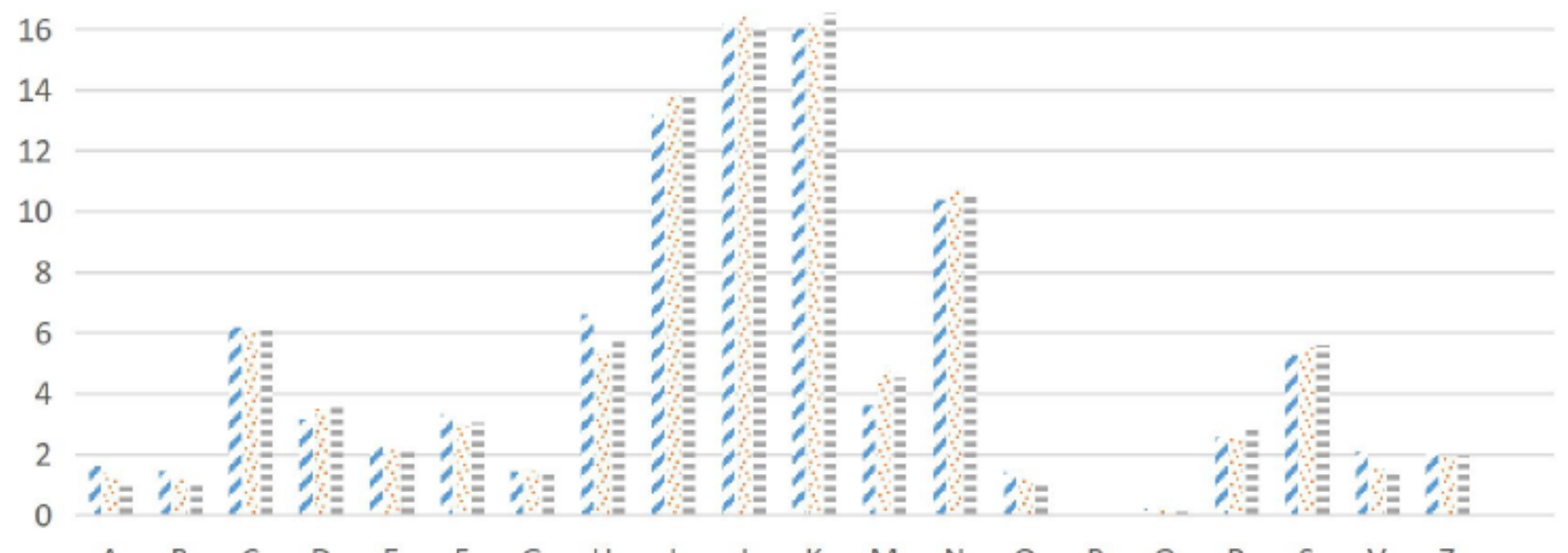

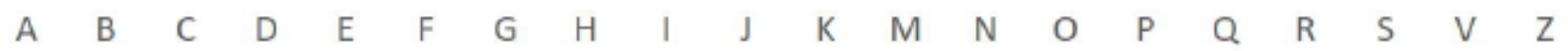
C. $2013(\%) \quad 2014(\%)=2015(\%)$

\section{Figure 1}

The ratio of hospitalization person-times in local medical institutions

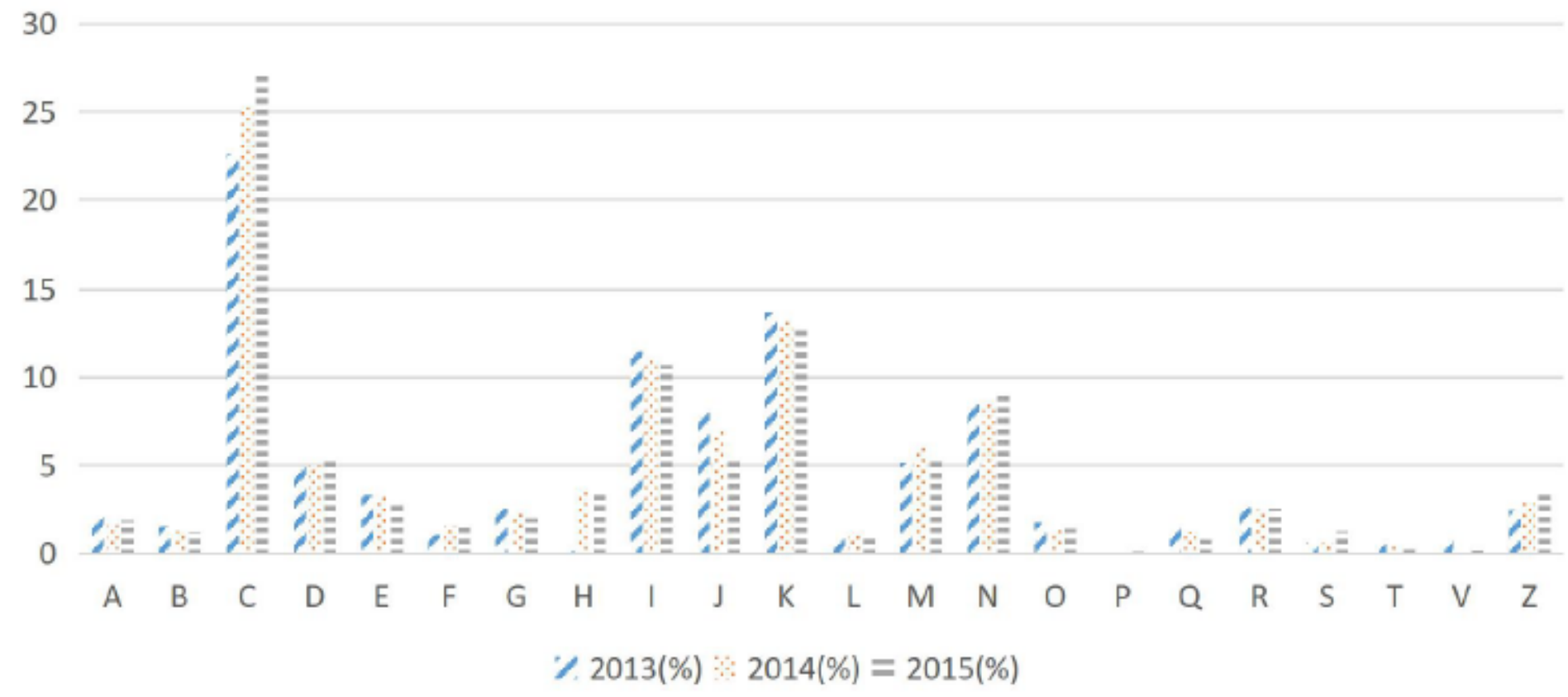

\section{Figure 2}

The ratio of hospitalization person-times in non-local medical institutions 